\title{
A CASE OF GOLDENHAR SYNDROME ASSOCIATED WITH GROWTH HORMONE DEFICIENCY
}

\author{
Yuichi Nakagawa, Hiromi Takeuchi, Akira Kubota, \\ Hiromune Natsume, Kaoru Nasuda, Akira Endoh, \\ Kazuhiko Toya, Haruo Ogawa, and Yoshio IgARAshi \\ Department of Pediatrics, Hamamatsu University School of Medicine, \\ Handa-cho, Hamamatsu 431-31, Japan
}

\begin{abstract}
Summary We have experienced the case of a 10-year-old boy who had Goldenhar syndrome accompanied by growth hormone (GH) deficiency. His height increased after treatment with growth hormone was administered. We found no untoward effects of the hormone and we consider that treatment with GH is useful for patients who present with Goldenhar syndrome associated with growth hormone deficiency.
\end{abstract}

Key Words Goldenhar syndrome, growth hormone treatment

\section{INTRODUCTION}

Goldenhar syndrome is characterized by microtia, mandibular hypoplasia, vertebral anomalies, and epibulbar dermoids (Goldenhar, 1952). However, to our knowledge there have been no reports concerning endocrinological abnormalities in Goldenhar syndrome. Here, we report the case of a boy with Goldenhar syndrome who also presented GH deficiency. We treated him with GH.

\section{CASE REPORT}

A ten-year-old boy was admitted to our hospital because of short stature and convulsions. He was born to healthy unrelated parents after a 38-week-uncomplicated term pregnancy and normal delivery. His apgar score was 9 points at 1 min. His birth weight was 2,290 $\mathrm{g}$ and he measured $48 \mathrm{~cm}$. He had been followed up at another hospital because of growth retardation and facial anomalies. He often showed generalized symmetrical tonic seizure from the age of 5 and had been treated with an anticonvulsant. He was referred to our hospital for the treatment of short stature and convulsions.

Received December 24, 1992; Revised Accepted March 17, 1993. 
Physical examination on admission showed left accesory auricle, microtia, left mandibular hypoplasia, left epibulbar dermoids and no mental retardation. Based on these findings he was having Goldenhar syndrome. His height was 100.8 $\mathrm{cm}$ ( -6.5 S.D.) and his body weight was $16 \mathrm{~kg}(-2.5$ S.D.). His father's height was $165 \mathrm{~cm}$ and his mother's height was $155 \mathrm{~cm}$. His only older brother was not short. None of the members of his family presented any of the abnormalities of the Goldenhar syndrome. His bone age was 4 years and 7 months. His thyroid and adrenal function were normal. His GH response to L-dopa and glucagon with propranolol was blunted (the highest level was 1.2 and $2.7 \mathrm{ng} / \mathrm{ml}$, respectively: normal level $>7 \mathrm{ng} / \mathrm{ml}$ ). His thyroid-stimulating hormone response to thyrotropin-releasing hormone as well as luteinizing hormone and follicle-stimulating hormone responses to luteinizing hormone-releasing hormone were all within normal range. Thus, based on the results of the endocrinologic examinations he was also diagnosed as having idiopathic GH deficiency.

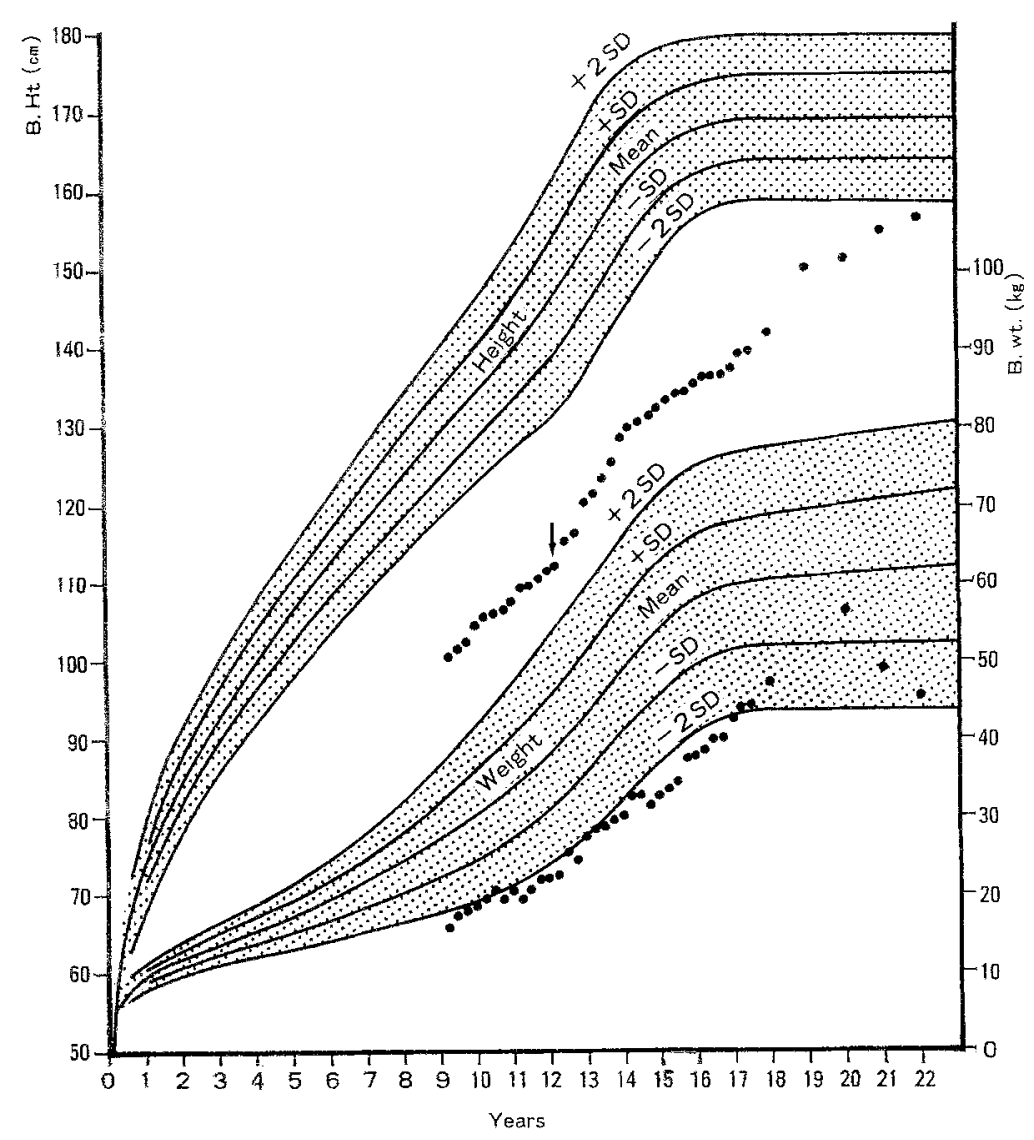

Fig. 1. Growth of a boy with Goldenhar syndrome ( $)$ in comparison with normal standards (gray shading). The arrow indicates the start of GH treatment. 
We began to treat him with sodium valproate $(400 \mathrm{mg} /$ day) for the convulsions and anabolic steroids ( $1 \mathrm{mg} /$ day) for short stature, because we could not immediately use GH. We began to treat him with $\mathrm{GH}(0.1 \mathrm{u} / \mathrm{kg} / \mathrm{wk})$ in addition to anabolic steroids when he was 12 years and 3 months old and continued the therapy for convulsions. His growth increased after GH treatment (Fig. 1). Signs of puberty were noted around the time he became 16 years old.

Now he is 23 years old but his bone age is delayed (16 years old). He is still under GH therapy and his height continues increasing. No untoward effects have been noted.

\section{DISCUSSION}

Goldenhar syndrome is an association of facial and auricular anomalies resulting from errors in the morphogenesis of the first and second branchial arches. This syndrome is also associated with pulmonary and airway-related malformations (Gorlin et al., 1963; Booth and Berry, 1975; Kenawi and Dickson, 1976; Bowen and Parry, 1980; Mendelberg et al., 1985; Scholtes et al., 1987; Smith, 1988; Downing and Kilbridge, 1991) but, in general it is not associated with growth retardation. To our knowledge there are no reports in the literature regarding its association with endocrinological abnormalities.

Turner syndrome and septo-optic dysplasia are characterized by short stature and are often associated with GH deficiency. Such patients are effectively treated with GH (Arslanian et al., 1984; Price et al., 1990; Rongen et al., 1990; Massa et al., 1991; Job and Landier, 1991). But in other syndromes associated with growth retardation, it is not known whether GH therapy is effective or not. Recently, Horton et al. (1992) reported that growth-promoting therapy with recombinant human GH for achondroplasia is safe and effective.

Our patient was short due to GH deficiency; thus we treated him with GH. He used to grow in height at the rate of $3 \mathrm{~cm} /$ year before $\mathrm{GH}$ being administered and after treatment with $\mathrm{GH}$ his height increased at a rate of $9 \mathrm{~cm} /$ year. His pubertal stage did not change after the GH treatment; therefore we did not change to other modes of treatments. Between the age of 18 and 20 years, his weight increased at a high rate due to unknown factors, but this increase in body weight was not considered as an adverse effect of $\mathrm{GH}$ because the other physical parameters did not change and laboratory data were normal.

In conclusion we consider that GH therapy was effective in this boy with Goldenhar syndrome associated with GH deficiency. To our knowledge, this is the first case in the world of Goldenhar syndrome associated with GH deficiency in whom GH therapy was attempted and it proved effective. 


\section{REFERENCES}

Arslanian SA, Rothfus WE, Foley TP, Becker DJ (1984): Hormonal, metabolic, and neuroradiologic abnormalities associated with septo-optic dysplasia. Acta Endocrinol (Copenh) 107: 282-288

Booth JB, Berry CL (1975): Unilateral pulmonary agenesis. Arch Dis Child 42: 361-374

Bowen AD, Parry WH (1980): Bronchopulmonary foregut malformation in the Goldenhar anomalad. AJR 134: 186-188

Downing GJ, Kilbridge H (1991): An interesting case presentation: pulmonary malformations associated with oculoauriculovertebral dysplasia (Goldenhar anomalad). J Perinatol 11: 190192

Goldenhar M (1952): Association malformative de l'oeil et de l'oreille, en particulier le syndrome dermoide epibulbaire-appendices auriculaires fistula auris congenita et ses relations avec la dysostose mandibulogaciale. J Genet Hum 1: 243-252

Gorlin RJ, Jue KL, Jacobsen V, Goldschmidt E (1963): Oculoauriculovertebral dysplasia. J. Pediatr 63: $991-999$

Horton WA, Hecht JT, Hood OJ, Marshall RN, Moore WV, Hollowell JG (1992): Growth hormone therapy in achondroplasia. Am J Med Genet 42: 667-670

Job JC, Landier F (1991): Three-year results of treatment with growth hormone, alone or associated with oxandrolone, in girls with Turner syndrome. Horm Res 35: 229--233

Kenawi MM, Dickson JAS (1976): Aplasia of the right lung and calcifying epithelioma in association with Goldenhar's syndrome. Postgrad Med J 52: 312-315

Massa G, Vanderschueren LM, Craen M, Vandeweghe M, Van VG (1991): Growth hormone treatment of Turner syndrome patients with insufficient growth hormone response to pharmacological stimulation tests. Eur J Pediatr 150: 460-463

Mendelberg A, Ariel I, Mogle P, Arad I (1985): Tracheooesophageal anomalies in the Goldenhar anomalad. J Med Genet 22: 149-150

Price DA, Ranke MB, Guilbaud O (1990): Growtb response in the first year of growth hormone treatment in prepubertal children with organic growth hormone deficiency: a comparison with idiopathic growth hormone deficiency. The executive scientific committee of the Kabi international growth study. Acta Paediatr Scand Suppl 370: 131-137

Rongen WC, Fokker MH, Wit JM, Schrama SM, Otten BJ, Oostdijk W, Delemarre HA, Gons $\mathrm{MH}$, Bot A (1990): Two-year results of treatment with methionyl human growth hormone in children with Turner syndrome. Acta Paediatr Scand 79: 658-663

Scholtes JL, Veyckeman F, VanObbergh L (1987): Neonatal anesthetic management of a patient with Goldenhar's syndrome with hydrocephalus. Anesth Intensive Care 15: 338-340

Smith DW (1988): Facio-auricular-vertebral spectrum. In: Smith DW (ed). Recognizable patterns of human malformation. WB Saunders, Philadelphia, pp 584-586 